\title{
Toluene induced hypokalaemia: case report and literature review
}

\author{
J R Baskerville, G A Tichenor, P B Rosen
}

\begin{abstract}
Generalised weakness is a common complaint. A case is presented of toluene induced hypokalaemia in a 22 year old woman who presented with generalised weakness. The effect of toluene and causes of weakness and hypokalaemia in this setting are discussed.

(Emerg Med f 2001;18:514-516)
\end{abstract}

Keywords: toluene; potassium; metabolic acidosis

The complaint of generalised weakness is common in the practice of emergency medicine. Often, objective findings are few and the diagnosis elusive. When a patient with objective, generalised motor weakness or paralysis presents, the differential diagnosis is more limited. A variety of electrolyte abnormalities have been associated with weakness. These include hypokalaemia, hyperkalaemia, hypercalcaemia, hypocalcaemic tetany, hyponatraemia, hypophosphataemia, and hypermagnesaemia.

Toluene has been a reported cause of hypokalaemia. We present a case of generalised weakness associated with hypokalaemia and toluene misuse.

\section{Case report}

A 22 year old Hispanic woman was transferred to our emergency department with the presumptive diagnosis of Guillain-Barré syndrome (GBS). Two days before admission she developed numbness and tingling in her thighs. Later that day, when she awoke from a nap, she was unable to get out of bed. She described muscle aches and severe weakness in all extremities. This persisted and worsened over the next two days until she was completely unable to care for herself. She required assistance to get out of bed and was unable to walk. She had control of her bowel and bladder function and was able to eat with assistance.

Two days before the onset of her symptoms, the patient was sniffing spray paint. She admits to inhaling spray paint as often as every few weeks. She denies other drug misuse, but drinks alcohol.

Her past medical history was significant for a motor vehicle accident resulting in a head injury 14 years previously. She had a craniotomy at that time, but the details are unknown. She had no known neurological deficit as a result. Since then she has had a seizure disorder for which she takes phenytoin. The patient denied fever, chills, or recent viral illness.

Upon arrival at our department, her temperature was $35.9^{\circ} \mathrm{C}$, heart rate was 81 beats/min, respiratory rate was 20 breaths/min, and blood pressure was $144 / 72 \mathrm{~mm} \mathrm{Hg}$. She was alert with normal mental status and seemed unusually nonchalant about her illness. She had a small contusion over her right eyebrow. The neck was supple without pain or tenderness. Heart, lung, and abdominal examination were normal with the exception of mild obesity. She had moderate tenderness in all the muscle compartments. Vascular examination was normal. The neurological examination showed normal cranial nerves. Sensation and proprioception were intact. Deep tendon reflexes were unobtainable. Strength was decreased in the trunk and extremities. She was not able to lift her head. Lower extremity distal motor strength was slightly decreased at $4 / 5$. Proximal muscles were 5/5, but limited because of muscle pain. Upper extremities were weaker with $2-3 / 5$ strength proximally, and 3/5 distally. She had normal rectal tone.

With the history of drug misuse and the forehead contusion, a traumatic spinal cord injury was considered. Thus, the patient was placed in a cervical collar and radiographs of the cervical spine were obtained, which were negative. The urine analysis showed a specific gravity of $1.015,1+$ blood, nitrite negative, $\mathrm{pH}$ -6.5 , trace protein, 2 to 5 red blood cells and 5 to 10 white blood cells per high power field. Urine drug screen was negative. Phenytoin level was less than $2.5 \mu \mathrm{g} / \mathrm{ml}$. Serum sodium was $141 \mathrm{mEq} / \mathrm{l}$, potassium was $1.4 \mathrm{mEq} / \mathrm{l}$, chloride was $111 \mathrm{mEq} / 1$, carbon dioxide was 23 $\mathrm{mEq} / 1$, blood urea nitrogen was $8 \mathrm{mg} / \mathrm{dl}$, creatinine was $0.6 \mathrm{mg} / \mathrm{dl}$, magnesium was $2.2 \mathrm{mg} / \mathrm{dl}$, phosphorous was $2.7 \mathrm{mg} / \mathrm{dl}$ and calcium was slightly low at $8.1 \mathrm{mg} / \mathrm{dl}$. Serum aspartate aminotransferase was $71 \mathrm{IU} / 1$, creatine kinase was $2460 \mathrm{IU} / 1$ (100\% MM), and $\mathrm{LDH}$ was 259 IU/1. An arterial blood gas measurement was taken shortly after potassium replacement had begun. It showed a pH of 7.42, $\mathrm{PCO}_{2}$ of $32 \mathrm{~mm}$ $\mathrm{Hg}, \mathrm{PO}_{2}$ of $102 \mathrm{~mm} \mathrm{Hg}, \mathrm{HCO}_{3}$ of $21 \mathrm{mmol} / 1$ and base excess of $-2.5 \mathrm{mmol} / 1$ on room air. Urine sodium was $53 \mathrm{mEq} / \mathrm{l}$, urine potassium was $24.3 \mathrm{mEq} / 1$, urine chloride was $143 \mathrm{mEq} / 1$, and urine creatinine was $143.7 \mathrm{mg} / \mathrm{dl}$. Serum aldosterone was $1 \mathrm{ng} / \mathrm{dl}$. The electrocardiogram showed prolonged Q-T interval and ST depression consistent with hypokalaemia.

\section{EMERGENCY DEPARTMENT AND HOSPITAL}

COURSE

Potassium replacement via oral and intravenous infusion was begun in the emergency department. In the next 36 hours she received $310 \mathrm{mEq}$ potassium, primarily orally, and her symptoms were completely resolved. At the 
time of discharge, her serum potassium concentration was $3.3 \mathrm{mEq} / \mathrm{l}$.

\section{Discussion}

This patient presented to us with a provisional diagnosis of GBS. GBS is an inflammatory peripheral neuropathy characterised clinically as an ascending paralysis or weakness of variable degrees progressing over several days to three weeks. ${ }^{1}$ The clinical presentation usually begins with distal paresthesias followed by leg weakness. The weakness progresses proximally over the course of several days, often involving facial, oropharyngeal or respiratory muscle weakness requiring mechanical ventilation. This is commonly accompanied by pain in the large muscles. Deep tendon reflexes are markedly diminished or absent and sensation is intact. The signs and symptoms in this patient mimicked GBS. The differential diagnosis to be considered in this clinical setting includes spinal cord compression, transverse myelitis, myasthenia gravis, polymyositis, metabolic myopathies, paraneoplastic neuropathy, hypophosphataemia, botulism, paralytic poliomyelitis, and tick paralysis. ${ }^{1}$

This patient's symptoms were attributable to profound hypokalaemia. Hypokalaemia is a well known, but uncommon cause of acute weakness. ${ }^{2}$ Muscle weakness is most prominent in the limbs with the respiratory cranial and bulbar usually spared. Deep tendon reflexes are usually diminished or absent. The differential diagnosis of hypokalaemia can be classified into four categories. These are inadequate intake, excessive gastrointestinal losses, intracellular shift, or renal causes. The renal causes include diuretics, mineralocorticoid excess (such as primary or secondary hyperaldosteronism, licorice ingestion, or Cushing's syndrome), Liddle's syndrome, or renal tubular acidosis. Intracellular shift can be caused by alkalosis, insulin excess, $\beta$ adrenergic excess, theophylline toxicity, thyrotoxic periodic paralysis, hypokalaemic periodic paralysis, and barium poisoning. ${ }^{2}$ The differentiation of these entities is beyond this article, however good reviews have been published. ${ }^{2}{ }^{3}$

Rhabdomyolysis, as indicated by the increased creatine phosphokinase was also present. This has been seen previously in association with hypokalaemia. ${ }^{4}$ It has also been seen in cases of toluene intoxication without hypokalaemia. A direct toxic effect of toluene on muscle membranes has been proposed, although this may simply result from direct muscle compression because of immobility. ${ }^{4}$

\section{TOLUENE EFFECTS}

Electrolyte and acid/base abnormalities after toluene inhalation have been reported. Taher et $a \bar{l}$ first reported two cases of metabolic acidosis in 1974. One of their patients had severe hypokalaemia. Other cases have since been reported. ${ }^{4-14}$ The serum potassium concentrations seen in 50 patients over 71 admissions averaged $2.9 \mathrm{mEq} / 1$ (range 1.1-4.5). The average serum $\mathrm{pH}$ was 7.2 (range 6.88-7.38), chloride was $113 \mathrm{mEq} / \mathrm{l}$ (range 88-127), and $\mathrm{CO}_{2}$ was $10.0 \mathrm{mEq} / 1$ (range $(0-21)$. The average anion gap (Na+K-Cl-CO2) was $16.6 \mathrm{mEq} / \mathrm{l}$ (range 8.6-41.6)

Many of these had presentations similar to our patient, yet some differences were noted. Our patient demonstrated hypokalaemia and hyperchloraemia with a borderline low bicarbonate and a normal anion gap. She had a potassium of $1.4 \mathrm{mEq} / \mathrm{l}$, which was the primary cause of her symptoms on presentation. Of the previously reported cases, there were approximately 16 occasions when the patient's presenting symptoms were similar to ours. More commonly, the patients had predominance of nausea, vomiting, or abdominal pain. Many also present with primarily neurological and mental status changes. In most cases, the patients are acidotic with a normal anion gap. These abnormalities have been attributed to distal renal tubular acidosis. This is supported by metabolic studies showing an inability to properly acidify the urine. ${ }^{78}$ Many patients, however, have an increased anion gap. This is not explained by distal renal tubular acidosis and indicates the production of an organic acid. Toluene has been found to be metabolised to the hippuric acid and benzoic acid. The enzyme that facilitates this reaction, cytochrome $\mathrm{P}-450$, is inducible. Thus, the rate of production of these acids may vary, depending on the chronicity of abuse, misuse of alcohol or other substances or amount of toluene inhaled. ${ }^{15}$ Some have suggested that a decreased glomerular filtration rate from decreased extracellular volume may cause mild prerenal failure. This would inhibit the kidney's ability to excrete these organic acids, adding to an increased gap. ${ }^{9} 15$

The cause of the hypokalaemia is also uncertain. Possible explanations include increased mineralocorticoid because of volume contraction, ${ }^{511}$ increased urinary excretion because of the presence of poorly reabsorbed anions and low urinary chloride concentration as would be seen with urinary excretion of hippurate and benzoic acid accompanied by volume contraction, and high urine flow rate because of the osmotic load of hippurate. ${ }^{515}$ One possible explanation for the very low potassium associated with the normal acid/base status in our patient was the care she received before seeking medical care. Her friends had been bringing her food and presumably liquids while she was unable to walk. This might have allowed her to maintain her intravascular volume and urine flow rate. She would have been able to excrete the hippurate and benzoic acid and correct a metabolic acidosis. In doing so, she would have further lowered her serum potassium by causing an intracellular shift and enhanced excretion. Her alcohol misuse and relative obesity may have increased the acidosis by inducing the cytochrome P-450 and by allowing a higher amount of toluene to be stored in the adipose tissue. $^{15}$

\section{TREATMENT}

Treatment of toluene exposure lies primarily in the correction of the resulting metabolic disorders. Most patients will require parenteral hydration and attention to renal function. Recovery is usually rapid with the correction of 
the electrolyte disorders. ${ }^{4}$ Bicarbonate replacement may be needed in severe acidosis with a $\mathrm{pH}$ less than 7.2 . $^{7}$

1 Ropper AH. The Guillain-Barré syndrome. $N$ Engl f Med 1992;326:1130-6.

2 Stedwell RE, Allen KM, Binder LS. Hypokalemic paralysis: A review of the etiologies, pathophysiologies, presentation, and therapy. Am f Emerg Med 1992;10:143-8.

3 Kamel KS, Quaggin S, Scheich A, et al. Disorders of potassium homeostasis: an approach based on pathophysiology. Am F Kidney Dis 1994;24:597-613.

Striecher HZ, Gabow PA, Moss AH, et al. Syndromes of toluene sniffing in adults. Ann Int Med 1981;94:758-62. 5 Taher SM, Anderson RJ, McCartney R, et al. Renal tubular 1974;290:765-8.

6 Bennett RH, Forman HR. Hypokalimic periodic paralysis in chronic toluene exposure. Arch Neurol 1980;37:673.

7 Voights A, Kaufman CE, Jr Acidosis and other metabolic abnormalities associated with paint sniffing. South Med $\mathcal{F}$ 1983;76:443-8.
8 Battlle DC, Sabatini S, Kurtzman NA. On the mechanism of toluene-induced renal tubular acidosis. Nephronology 1988;49:210-18.

9 Fischman CM, Oster JR. Toxic effects of toluene, a new cause of high anion gap metabolic acidosis. $7 A M A$ 1979;241:1713-15.

10 Moss AH, Gabow PA, Kaehny WD, et al. Fanconie's syndrome and sital renal tubular acidosis after glue sniffing. Ann Intern Med 1980;92:69-70.

11 Davidman M, Schmitz P. Renal tubular acidosis. A pathophysiologic approach. Hosp Pract 1988;23:77-81, $84-8,93-6$.

12 Jone $\mathrm{CM}$, Wu AH. An unusual case of toluene-induced metabolic acidosis. Clin Chem 1988;34:2596-9.

13 Patel R, Benjamin J. Renal disease associated with toluene inhalation. Clin Toxicol 1986;24:213-23.

14 Kamijima M, Nakazawa Y, Yamakawa M, et al. Metabolic acidosis and renal tubular injury due to pure toluene inhalation. Arch Environ Health 1994;49:410-13.

15 Carlisle EJF, Donnelly SM, Vasuvattakul S, et al. Gluesniffing and distal renal tubular acidosis: sticking to the facts. F Am Soc Nephrol 1991;1:1019-27. 